\title{
Novel non-synonymous polymorphisms in the COX-1 gene in Turkish pediatric patients with cardiovascular anomalies
}

\author{
I. Coskun ${ }^{1}$, Y. Colkesen ${ }^{2}$, F. Ayik ${ }^{3}$, A. Berdeli ${ }^{4}$ and Y. Atay ${ }^{3}$ \\ ${ }^{1}$ Department of Cardiovascular Surgery, Baskent University, \\ Faculty of Medicine, Adana, Turkey \\ ${ }^{2}$ Department of Cardiology, Baskent University, Faculty of Medicine, \\ Adana, Turkey \\ ${ }^{3}$ Department of Cardiovascular Surgery, Ege University, \\ Faculty of Medicine, Izmir, Turkey \\ ${ }^{4}$ Molecular Medicine Laboratory, Department of Pediatrics, \\ Ege University, Faculty of Medicine, Izmir, Turkey \\ Corresponding author: I. Coskun \\ E-mail: icoskun1974@gmail.com
}

Genet. Mol. Res. 13 (1): 262-268 (2014)

Received January 7, 2013

Accepted May 17, 2013

Published January 17, 2014

DOI http://dx.doi.org/10.4238/2014.January.17.10

\begin{abstract}
Variation in the gene encoding cyclooxygenase-1 $(\mathrm{COX}-1)$ is involved in the process of aspirin resistance. This study investigated the genetic variations in the COX-1 gene. The 4 coding regions of the human $\mathrm{COX}-1$ gene in 90 pediatric patients (median age of 6.5 months, 55\% males) with cardiovascular anomalies were screened using DNA sequencing. Twenty coding-region variants causing amino acid substitutions as well as 2 new non-synonymous polymorphisms were identified. All variants were compared with an independent Caucasian population ( $\mathrm{N}=24$ unrelated individuals). Most of the discovered polymorphisms were rare, although some variants resulted in amino acid changes occurring at a frequency $>5 \%$ (W8R, P17L, Q41Q, Q240Q, D189E, and P188P). In addition, 2 new non-
\end{abstract}


synonymous polymorphisms (F200L and D189E) were identified. These findings demonstrated novel genetic variants of the human COX1 gene. Future studies characterizing the functional impact of these variants are warranted.

Key words: COX-1; Gene; Polymorphism

\section{INTRODUCTION}

For primary and secondary prophylaxis, pediatric patients with cardiovascular anomalies are administered aspirin to prevent arterial vascular events (Monagle et al., 2008). In children receiving aspirin for diverse indications, incidence of laboratory and clinical aspirin resistance following pediatric cardiac surgery was estimated at 2.3\% (Yee et al., 2008) and $10 \%$ (Cholette et al., 2010), respectively. Aspirin responsiveness can be influenced by polymorphisms in the gene encoding the cyclooxygenase-1 (COX-1) enzyme, causing amino acid substitutions that could change the specific activity of COX-1 (Halushka et al., 2003).

The COX-1 gene has been localized to chromosome 9q32-q33.3 and has been cloned (Yokoyama and Tanabe, 1989). The gene consists of 11 exons (Funk et al., 1991). Polymorphisms in both coding and non-coding regions of the human COX-1 gene have been identified (Ulrich et al., 2002), and the COX-1 gene has been re-sequenced as part of the Seattle singlenucleotide polymorphism (SNP) Variation Discovery Resource (http://pga.mbt.washington. edu/). In particular, non-synonymous variants encoding amino acid substitutions in the COX-1 protein have been identified (Scott et al., 2002).

We screened the 4 coding regions of the human COX-1 gene in pediatric patients with cardiac anomalies for SNPs, using DNA sequencing. Our primary objective was to identify or confirm the existence of SNPs in the COX-1 gene. Subsequently, we determined the allele frequencies of the observed polymorphisms and discovered 2 new non-synonymous polymorphisms.

\section{MATERIAL AND METHODS}

\section{Patient selection}

In the presented study, we enrolled 90 pediatric patients (50 males and 40 females), with cardiovascular anomalies, who were candidates for operative surgery. Twenty-four healthy unrelated adults were control subjects. All 114 subjects were Caucasians and from the Aegean region of Turkey.

We sequenced 4 of the 11 exons of the COX-1 gene in 90 patients and identified 2 novel non-synonymous polymorphisms.

\section{DNA extraction and PCR amplification}

Genomic DNA was extracted from peripheral blood by using a DNA extraction kit (Invitrogen, Carlsbad, CA, USA) following a standard protocol (Miller et al., 1988). To identify polymorphisms, the coding exons of COX-1 were amplified individually. The primer sequences, $\mathrm{MgCl}_{2}$ concentrations, and annealing temperatures for each amplicon are listed in 
Table 1. Each reaction was amplified with a $25-\mu \mathrm{L}$ mixture containing $2.5 \mu \mathrm{L} 10 \mathrm{X}$ PCR buffer with variable $\mathrm{MgCl}_{2}$ concentrations [Applied Biosystems (ABI), Foster City, CA, USA], 2.5 $\mathrm{mM}$ dNTPs, $10 \mathrm{pM}$ of each primer, $0.7 \mathrm{U}$ Taq DNA polymerase (Roche, Mannheim, Germany), and 100 ng genomic DNA. Thermal cycling was performed using a thermal cycler (Applied Biosystems 9700) as follows: initial denaturation for $12 \mathrm{~min}$ at $95^{\circ} \mathrm{C} ; 35$ cycles at $94^{\circ} \mathrm{C}$ for $30 \mathrm{~s}, 62^{\circ} \mathrm{C}$ (exons 2 and 3 ) or $60^{\circ} \mathrm{C}$ (exons 6 and 7 ) for $30 \mathrm{~s}, 72^{\circ} \mathrm{C}$ for $30 \mathrm{~s}$; and a final extension for $10 \mathrm{~min}$ at $72^{\circ} \mathrm{C}$.

\begin{tabular}{|c|c|c|c|c|}
\hline Exons & Primers & $\mathrm{MgCl}_{2}(\mathrm{mM})$ & Annealing temperature $\left({ }^{\circ} \mathrm{C}\right)$ & Amplicon length (bp) \\
\hline 2 & $\begin{array}{l}\text { Cox1-2112F: 5'-ATGAGCCGTGAGTGCGACCC-3' } \\
\text { Cox1-2462R: 5'-GCTTCAGGGAGCCCCCATC-3' }\end{array}$ & 1.2 & 66 & 351 \\
\hline 3 & $\begin{array}{l}\text { Cox1-8816F: 5'-GAGCTGCGACTTAAGTCCAT-3' } \\
\text { Cox1-9123R: 5'-GGAAGTTAGGGTCTAGGAGA-3' }\end{array}$ & 1.5 & 62 & 308 \\
\hline 6 and 7 & $\begin{array}{l}\text { Cox1-12346F: 5'-GCAGCAAGATCCAGATAGGA-3' } \\
\text { Cox1-12872R: 5'-CTCTCAGGACATGACCCAGA-3' }\end{array}$ & 1.0 & 62 & 527 \\
\hline
\end{tabular}

\section{DNA sequencing}

All the amplified products were sequenced bidirectionally using BigDye Terminator Mix version 3.1 (Applied Biosystems), according to manufacturer instructions, and were analyzed on an ABI-3100 Genetic Analyzer (ABI). Nucleotide sequences were compared with the published COX-1 gene cDNA sequence in the PARSESNP database (Greene E and Taylor N; http://www.proweb.org/parsesnp).

The study was approved by the Ege University Institutional Review Board and conducted according to the ethical principles in the Declaration of Helsinki and Good Clinical Practice guidelines. A written informed consent was obtained from parents and each individual.

Statistical analyses were performed with the SPSS statistical package (version 17.0, SPSS, Chicago, IL, USA). All numerical data are expressed as median (interquartile range) values or proportions. Categorical variables are presented as number of cases (percentage) and are compared using the chi-square test. Two-sided $\mathrm{P}$ values of less than 0.05 were regarded as significant.

\section{RESULTS}

The median age was 6.5 months, with an interquartile range of 1 day to 16 years. Of these, $8(8.8 \%)$ patients had vascular anomalies such as patent ductus arteriosus $(2.2 \%)$, aberrant subclavian artery (2.2\%), and aortic coarctation (4.4\%). Eighty-two (91.2\%) patients had diverse cardiac anomalies (Table 2). The median age was 31 years (18-43) in the control group.

Sequencing of exons 2, 3, 6, and 7 of the COX-1 gene from the 90 pediatric patients of known ethnicity identified 20 SNPs. Of these, 7 SNPs were located in exon 2, 8 were located in exon 3, and 5 were located in exons 6 and 7. The most frequent SNP was W8R in both groups (95.6 and $87.5 \%$, respectively; $\mathrm{P}=0.14$ ).

In all subjects, the total number of amino acid substitutions was 143 (73\%), and the total number of SNPs was 54 (27\%); in the study group, the frequencies were 72 and $28 \%$, respectively. The most frequent amino acid substitutions were tryptophan to arginine (W8R) (93.9\%) and proline to proline (P188P) (28.1\%) (Table 3). 
Table 2. Operated patients with congenital cardiovascular anomalies.

\begin{tabular}{lc}
\hline Cardiac and vascular anomalies & $\mathrm{N}=90(\%)$ \\
\hline Single ventricule & $14(15.6)$ \\
ASD & $13(14.5)$ \\
TGV & $11(12.3)$ \\
Tetralogy of Fallot & $11(12.3)$ \\
VSD & $7(7.7)$ \\
Truncus arteriosus & $4(4.5)$ \\
Aortic coarctation & $4(4.5)$ \\
Subaortic discrete membrane & $3(3.3)$ \\
VSD + ASD & $2(2.2)$ \\
Aberrant subclavian artery & $2(2.2)$ \\
ASD + PAPVR & $2(2.2)$ \\
Pulmonary stenosis & $2(2.2)$ \\
A-V canal defect & $2(2.2)$ \\
VSD + PDA + PFO & $2(2.2)$ \\
PDA & $2(2.2)$ \\
TAPVR & $2(2.2)$ \\
ASD + VSD + TGV & $2(2.2)$ \\
Aortic valve stenosis & $1(1.1)$ \\
IHSS + mitral valve insufficiency & $1(1.1)$ \\
Hipoplastic left heart & $1(1.1)$ \\
VSD + pulmonary atresia & $1(1.1)$ \\
Cor triatriatum sinistrum & $1(1.1)$ \\
\hline ASD = atrial septal defect; TGV = transposition of the great vessels; VSD $=$ ventricular septal defect; PAPVR = partial \\
anomalous pulmonary venous return; A-V = atrio-ventricular; PFO = patent foramen ovale; PDA = patent ductus \\
arteriosus; TAPVR = total anomalous pulmonary venous return; IHSS = idiopathic hypertrophic subaortic stenosis.
\end{tabular}

Table 3. Distribution of amino acid substitutions and polymorphisms in all subjects.

\begin{tabular}{llllrrr}
\hline Exons & AA substitution & Codon & NC & AA substitution & N $=114$ & $\%$ \\
\hline 2 & Tryptophan/arginine & TGG/CGG & T-C & W8R & 107 & 93.9 \\
& Proline/leucine & CCG/CTG & C-T & P17L & 6 & 5.3 \\
& Leucine/proline & CTG/CCG & T-C & L13P & 2 & 1.8 \\
& Leucine/leucine & CTC/CTG & C-G & L23L & 1 & 0.9 \\
& Proline/arginine & CCG/CGG & C-G & P18R & 1 & 0.9 \\
& Leucine/tyrosine & CTG/GTG & C-G & L15Y & 2 & 1.8 \\
& Glutamine/glutamine & CAG/CAD & G-A & Q41Q & 7 & 6.1 \\
& Proline/proline & CCA/CCC & A-C & P39P & 2 & 1.8 \\
Arginine/arginine & CGC/CGA & C-A & R53R & 1 & 0.9 \\
& Arginine/serine & CGC/AGC & C-A & G44G & 1 & 0.9 \\
& Cysteine/tryptophan & TGC/TGG & C-G & C58W & 2 & 1.8 \\
& Isoleucine/methionine & ATC/ATG & C-G & I45M & 1 & 0.9 \\
& Arginine/histidine & CGC/CAC & G-A & R53H & 1 & 0.9 \\
& Glycine/glycine & GGC/GGT & C-T & G62G & 1 & 0.9 \\
& Glutamine/glutamine & CAG/CAA & C-A & Q240Q & 6 & 5.3 \\
& Arginine/leucine & CGT/CTT & G-T & R239L & 2 & 1.8 \\
& Phenylalanine/leucine & TTT/TTG & T-G & F200L & 1 & 0.9 \\
& Aspartic acid/glutamic acid & GAC/GAG & C-G & D189E & 20 & 17.5 \\
& Lysine/threonine & AAG/ACG & A-C & K185T & 1 & 0.9 \\
& Proline/proline & CCT/CCC & C-C & P188P & 32 & 28.1 \\
\hline
\end{tabular}

$\mathrm{AA}=$ amino acids; $\mathrm{NC}=$ nucleotide change.

All variants were compared with an independent Caucasian population $(\mathrm{N}=24$ unrelated individuals) (Table 4). Two new SNPs were detected, F200L and D189E, encoded in exons 6 and 7, respectively. F200L was observed in 1 patient $(1.1 \%)$ and only in the study group $(\mathrm{P}=0.60)$. The frequency of the $\mathrm{D} 189 \mathrm{E} \mathrm{SNP}$ was 18.9 and $12.5 \%$ in the study and control groups, respectively $(\mathrm{P}=0.46)$. 


\begin{tabular}{|c|c|c|c|c|c|c|}
\hline \multirow[t]{2}{*}{ Exons } & \multirow[t]{2}{*}{ Codon } & & \multirow[t]{2}{*}{ Amino acid substitution } & \multicolumn{3}{|c|}{ Variant allele frequency } \\
\hline & & & & Study group $[N=90(\%)]$ & Controls $[\mathrm{N}=24(\%)]$ & $\mathrm{P}$ \\
\hline \multirow[t]{6}{*}{2} & TGG/CGG & $\mathrm{HOM}$ & W8R (Trp8Arg) & $86(95.6)$ & $21(87.5)$ & 0.14 \\
\hline & $\mathrm{CCG} / \mathrm{CTG}$ & HET & P17L (Pro17Leu) & $6(6.7)$ & 0 & 0.19 \\
\hline & $\mathrm{CTG} / \mathrm{CCG}$ & HET & L13P (Leu13Pro) & $2(2.2)$ & 0 & 0.46 \\
\hline & $\mathrm{CTC} / \mathrm{CTG}$ & HET & L23L (Leu23Leu) & $1(1.1)$ & 0 & 0.60 \\
\hline & $\mathrm{CCG} / \mathrm{CGG}$ & HET & P18R (Pro18Arg) & $1(1.1)$ & 0 & 0.60 \\
\hline & CTG/GTG & HET & L15Y (Leu15Tyr) & $1(1.1)$ & $1(4.2)$ & 0.31 \\
\hline \multirow[t]{8}{*}{3} & $\mathrm{CAG} / \mathrm{CAA}$ & HET & Q41Q (Gln41Gln) & $5(5.6)$ & $2(8.4)$ & 0.61 \\
\hline & $\mathrm{CCA} / \mathrm{CCC}$ & HET & P39P (Pro39Pro) & $2(2.2)$ & 0 & 0.46 \\
\hline & $\mathrm{CGC} / \mathrm{CGA}$ & HET & R53R (Arg53Arg) & $1(1.1)$ & 0 & 0.60 \\
\hline & $\mathrm{GGC} / \mathrm{GGG}$ & HET & G44G (Gly44Gly) & $1(1.1)$ & 0 & 0.60 \\
\hline & TGC/TGG & HET & C58W (Cys58Trp) & $2(2.2)$ & 0 & 0.46 \\
\hline & ATC/ATG & HET & I45M (Ile45Met) & $1(1.1)$ & 0 & 0.60 \\
\hline & $\mathrm{CGC} / \mathrm{CAC}$ & HET & R53H (Arg53His) & $1(1.1)$ & 0 & 0.60 \\
\hline & GGC/GGT & HET & G62G (Gly62Gly) & $1(1.1)$ & 0 & 0.60 \\
\hline \multirow[t]{6}{*}{6 and 7} & $\mathrm{CAG} / \mathrm{CAA}$ & HOM & Q240Q (Gln240Gln) & $6(6.7)$ & 0 & 0.19 \\
\hline & CGT/CTT & HOM & R239L (Arg239Leu) & $2(2.2)$ & 0 & 0.46 \\
\hline & TTT/TTG & HET & F200L (Phe200Leu) & $1(1.1)$ & 0 & 0.60 \\
\hline & $\mathrm{GAC} / \mathrm{GAG}$ & HET & D189E (Asp189Glu) & $17(18.9)$ & $3(12.5)$ & 0.46 \\
\hline & $\mathrm{AAG} / \mathrm{ACG}$ & HET & K185T (Lys185Thr) & $1(1.1)$ & 0 & 0.60 \\
\hline & $\mathrm{CCT} / \mathrm{CCC}$ & HET & P188P (Pro188Pro) & $31(34.4)$ & $1(4.2)$ & 0.002 \\
\hline
\end{tabular}

HOM $=$ homozygote; HET $=$ heterozygote.

Most of the discovered polymorphisms were rare, although some variants resulting in amino acid substitutions occurred at a frequency $>5 \%$ : W8R, P17L, Q41Q, Q240Q, D189E, P188P. The polymorphisms found only in the study group corresponded to P17L, L13P, L23L, P18R, P39P, R53R, G44G, C58W, I45M, R53S, G62G, Q240Q, R239L, F200L, and K185T. In control subjects, W8R, L15Y, Q41Q, D189E, and P188P polymorphisms were observed. Only the $\mathrm{P} 188 \mathrm{P}$ amino acid substitution was statistically more frequent in the study group than in the control group (34.4 vs $4.2 \%$, respectively, $\mathrm{P}=0.002)$.

\section{DISCUSSION}

The present study reports the screening of the coding region of the COX-1 gene, identification of polymorphisms, their allele frequencies in congenital anomalous patients and healthy individuals. We here report on 2 new non-synonymous polymorphisms resulting in amino acid substitutions. To our knowledge, this is the first report of allele frequencies on COX-1 polymorphisms in pediatric patients with cardiovascular anomalies.

COX-1 is the primary target of aspirin. Genetic variants that affect enzyme function, or the protein's interaction with aspirin, could alter an individual's drug response. Polymorphisms may increase the risk of cardiovascular disease or aspirin resistance (Halushka et al., 2003). It is unclear whether common variants affect the structure and function of the mature enzyme. Thus, it is believed that the differences seen in the function of COX-1 most likely result from genetic variation in the regulatory or signal peptide region of the gene or from variation in platelet development and aging. Effects of such variation would hypothetically affect either the amount of COX-1 protein or the location of COX-1 protein in the cell (Halushka et al., 2003; Lee et al., 2007). COX-1 structure-function studies suggest that several amino acid substitutions with modest influence on arachidonic acid binding to the COX-1 active site can alter the catalytic efficiency and metabolite profile of COX-1-mediated arachidonic acid 
metabolism (Thuresson et al., 2001). Perhaps these variants could reduce overall metabolic efficiency by altering the interaction between arachidonic acid and the active site. Functional studies aid in the interpretation of genetic epidemiological studies evaluating associations between COX-1 gene polymorphisms and the risk of diseases that involve altered COX-1-derived prostaglandin synthesis, such as cardiovascular and cerebrovascular disease (Lee et al., 2008; Lordkipanidzé et al., 2011).

Few non-synonymous coding polymorphisms in the COX-1 gene were discovered, and most of these were rare $(<5 \%)$, based on preliminary allele frequency determinations. We were not able to confirm the 2 new non-synonymous polymorphisms reported in the PARSESNP database (F200L and D189E).

In summary, we reported 2 new polymorphisms in the COX-1 gene and showed the allele frequencies of the new and previously described variants for pediatric patients with cardiovascular anomalies. Because the COX-1 enzyme is important in the pharmacology of aspirin, genetic polymorphisms that alter enzyme function are of interest. Further studies of the functional impact of the 2 new polymorphisms on aspirin metabolism are needed.

While the finding of novel polymorphisms in the COX-1 gene is potentially interesting, there are certain limitations. This is a partial screening of the COX-1 gene-coding regions. Although the patient population was given aspirin to prevent arterial vascular events, the functional impact of polymorphisms with respect to the aspirin-resistance in patients with polymorphisms was not investigated.

\section{Conflicts of interest}

The authors declare no conflict of interest.

\section{REFERENCES}

Cholette JM, Mamikonian L, Alfieris GM, Blumberg N, et al. (2010). Aspirin resistance following pediatric cardiac surgery. Thromb. Res. 126: 200-206.

Funk CD, Funk LB, Kennedy ME, Pong AS, et al. (1991). Human platelet/erythroleukemia cell prostaglandin G/H synthase: cDNA cloning, expression, and gene chromosomal assignment. FASEB J. 5: 2304-2312.

Halushka MK, Walker LP and Halushka PV (2003). Genetic variation in cyclooxygenase 1: effects on response to aspirin. Clin. Pharmacol. Ther. 73: 122-130.

Lee CR, Bottone FG Jr, Krahn JM, Li L, et al. (2007). Identification and functional characterization of polymorphisms in human cyclooxygenase-1 (PTGS1). Pharmacogenetics Genom. 17: 145-160.

Lee CR, North KE, Bray MS, Couper DJ, et al. (2008). Cyclooxygenase polymorphisms and risk of cardiovascular events: the Atherosclerosis Risk in Communities (ARIC) study. Clin. Pharmacol. Ther. 83: 52-60.

Lordkipanidzé M, Diodati JG, Palisaitis DA, Schampaert E, et al. (2011). Genetic determinants of response to aspirin: appraisal of 4 candidate genes. Thromb. Res. 128: 47-53.

Miller SA, Dykes DD and Polesky HF (1988). A simple salting out procedure for extracting DNA from human nucleated cells. Nucleic Acids Res. 16: 1215.

Monagle P, Chalmers E, Chan A, DeVeber G, et al. (2008). Antithrombotic therapy in neonates and children: American College of Chest Physicians Evidence-Based Clinical Practice Guidelines. 8th edn. Chest 133: 887S-968S.

Scott BT, Hasstedt SJ, Bovill EG, Callas PW, et al. (2002). Characterization of the human prostaglandin H synthase 1 gene (PTGS1): exclusion by genetic linkage analysis as a second modifier gene in familial thrombosis. Blood Coagul. Fibrinolysis 13: 519-531.

Thuresson ED, Lakkides KM, Rieke CJ, Sun Y, et al. (2001). Prostaglandin endoperoxide H synthase-1: the functions of cyclooxygenase active site residues in the binding, positioning, and oxygenation of arachidonic acid. J. Biol. Chem. 276: $10347-10357$. 
Ulrich CM, Bigler J, Sibert J, Greene EA, et al. (2002). Cyclooxygenase 1 (COX1) polymorphisms in African-American and Caucasian populations. Hum. Mutat. 20: 409-410.

Yee DL, Dinu BR, Sun CW, Edwards RM, et al. (2008). Low prevalence and assay discordance of "aspirin resistance" in children. Pediatr. Blood Canc. 51: 86-92.

Yokoyama C and Tanabe T (1989). Cloning of human gene encoding prostaglandin endoperoxide synthase and primary structure of the enzyme. Biochem. Biophys. Res. Commun. 165: 888-894. 